\title{
Funding Public Goods with Lotteries: Experimental Evidence
}

\author{
John Morgan and Martin Sefton \\ January 1996 \\ Revised June 1997
}

\begin{abstract}
Why do individuals participate in charitable gambling and state-run lotteries? In contrast to previous explanations that rely on risk-preference or pure love of gambling motives, we present a model where risk-neutral expected utility maximizers explicitly recognize that lotteries are being used to finance public goods. The model predicts that: a) individuals have an incentive to purchase lottery tickets; b) such a lottery will generate greater public good provision than would be attained from voluntary contributions; c) net of the cost of prizes, public goods provision is increasing in prize amounts; and d) lotteries cannot be used to finance socially undesirable public goods. We then investigate the efficacy of the lottery mechanism in laboratory public good environments. The first experiment we report involves a sharp test of the prediction that lotteries will out-perform voluntary contributions. In our voluntary contribution treatment, subjects' contributions to public goods average around 25-30\% of endowments (compared with a dominant strategy prediction of zero contributions). In our lottery treatment we introduce a lottery into this environment and find average contributions to be well predicted by the Nash equilibrium. After accounting for the cost of awarding prizes in the lottery, we find that the lottery mechanism increases public good provision, as predicted. We investigate the robustness of this result in a second public good experiment. Again, we find that the introduction of lotteries does indeed alleviate free-riding. We also find, as predicted, that ticket purchases vary with the size of the fixed prize and with the return from the public good: lotteries with large prizes are more effective, and ticket purchases drop dramatically when the public good is not valued by subjects.
\end{abstract}

JEL Classification Nos. D44, H41

Keywords: Public Goods, Lotteries, Experiments

\footnotetext{
${ }^{\dagger}$ We would like to thank Mike Baye, Rachel Croson, and seminar participants in Toulouse, Tel Aviv, LSE, Tilburg, and Chicago for helpful comments. We offer special thanks to John Cooper, Heather Morgan, Phillip and Mary Beth Stocken for their assistance in conducting some of the experiments. Finally, we would like to thank the Smeal College of Business, the Center for Research and Conflict Negotiation, the Woodrow Wilson School, and the University of Iowa for their generous support.

*** Morgan: Woodrow Wilson School, Princeton University; Sefton: School of Economic Studies, University of Manchester.
} 


\section{Introduction}

In the non-profit sector, devising effective means of raising funds through voluntary contributions is essential to the ability of organizations to provide public services to their communities. For many groups, direct solicitations for funds constitute the bulk of these fund-raising efforts; however, charitable gambling is also a significant revenue generating instrument. In Britain, for instance, private charities raise about $8 \%$ (or $£ 500$ million) of their income through lotteries. ${ }^{1}$ In the US in 1992, among 26 reporting states, about $\$ 6$ billion was raised by private charities through lotteries. ${ }^{2}$ Since only 26 states report revenues from charitable gambling, the $\$ 6$ billion represents a substantial underestimate of the size of this phenomenon. Certainly, the prevalence of bingo and casino nights as well as raffles and other forms of charitable gambling suggest that lotteries are an important means of raising funds.

Governments are also increasingly turning to lotteries to complement tax-based forms of revenue generation. In the US, under the auspices of state governments, lotteries are frequently proposed in response to de facto or de jure restriction on increases in taxation, and state-run lotteries now account for more than $\$ 17$ billion of additional revenues to state treasuries. In short, lotteries are frequently employed as a voluntary mechanism in lieu of or in addition to other confiscatory mechanisms.

While most previous studies of lotteries have focused on equity aspects of their use by governments relative to forms of confiscatory taxation (see Clotfelter and Cook (1989) for a survey), the focus of this paper is on the efficiency of lotteries relative to other voluntary mechanisms. Viewed in this light, a much different set of questions about the performance of lotteries is suggested: Will risk-neutral expected utility maximizers ever have an incentive to purchase lottery tickets with negative expected values? How effective are lotteries in financing public goods? When are lotteries more effective than other voluntary schemes for providing public goods? In this paper, we examine these questions both from a theoretical and experimental perspective.

We develop and test a model of equilibrium wagering in lotteries whose proceeds (net of prize amounts) are being used to finance a public good. In contrast to the explanations about lottery play which depend upon misperceptions of risk, risk-seeking behavior, or pure love of gambling, we choose to focus on the effect of the public good in inducing risk neutral expected utility maximizers to participate in a lottery. In fact, when it is efficient to provide positive amounts of the public good, the lottery is predicted to provide (strictly) more of the public good than direct solicitations. Moreover, when it is inefficient to provide the public good, lottery ticket purchases are predicted to be insufficient to cover prizes, leaving no surplus for public good provision. With these theoretical predictions in hand, the remainder of the paper presents experimental tests of the main implications of the theory.

The first experiment we report involves a sharp test of the prediction that lotteries will outperform voluntary contributions. In our voluntary contribution treatment, subjects' contributions to public goods average around $25-30 \%$ of endowments (compared with a dominant strategy prediction of zero contributions). In our lottery treatment we introduce a lottery into this environment and find average contributions to be well predicted by the Nash equilibrium. After accounting for the cost of awarding prizes in the lottery, we find that the lottery mechanism increases public good provision, as predicted. We investigate the robustness of this result in a second public good experiment. Again, we find that the introduction of lotteries does indeed

\footnotetext{
${ }^{1}$ Douglas, Table IV, p. 87.

${ }^{2}$ Douglas, p. 357.
} 
alleviate free-riding. We also find, as predicted, that ticket purchases vary with the size of the fixed prize and with the return from the public good: lotteries with large prizes are more effective, and ticket purchases drop dramatically when the public good is not valued by subjects.

The paper proceeds as follows: Section 2 presents the theory underlying the experiment and analyzes the equilibria arising under the VCM and the lottery. In section 3, we discuss the structure of our experiment. Section 4 presents the results of the experiment. In section 5, we draw conclusions.

\section{Theory}

\subsection{The Model}

Consider a group of $N$ individuals and two goods. The first good, which may be thought of as wealth, is treated as the numeraire. The second good is a pure public good into which wealth may be transformed on a one-for-one basis. Individuals in this group are assumed to have linear utility (payoff) specifications of the form:

$$
\pi_{i}=w_{i}+\beta_{i} G,
$$

where $w_{i}$ denotes the wealth of agent $i$ and $G$ denotes the amount of the public good provided. The parameter $\beta_{1}$ denotes agent $i$ 's marginal utility for the public good. Notice that, since $G$ is a pure public good, then all individuals receive the marginal benefit $\beta_{j}$ for each unit of wealth contributed to the public good. We assume that for all $i \beta_{1}<1$, that is, an individual's return on a unit of personal wealth exceeds the marginal return of investing in the public good.

We begin by considering the social optimum. With $N$ individuals, each endowed with initial wealth $e_{i}$, the level of the public good, $G$, which maximizes aggregate social surplus is attained when $G \in\left\lfloor 0, \sum_{i=1}^{N} e_{i}\right\rfloor$ maximizes

$$
W=\sum_{i=1}^{N} e_{i}-G+G \sum_{i=1}^{N} \beta_{i}
$$

Naturally, if $\sum_{i=1}^{N} \beta_{i} \geq 1$, then it is optimal to allocate all of the resources in the group into the production of the public good; otherwise it is optimal to allocate none of the resources of the group to the production of the public good.

We now consider equilibrium provision of the public good in the VCM. In this mechanism, individuals simultaneously choose an amount of their wealth to contribute to the public good. The total amount chosen by all individuals is then transferred to the production of the public good and payoffs are realized. Thus, given the contributions by all other individuals, individual $i$ chooses an amount $x_{i} \in\left[0, e_{i}\right]$ of his wealth to contribute to the public good to maximize

$$
\pi_{i}=e_{i}-x_{i}+\beta_{i} \sum_{j=1}^{N} x_{j} .
$$

It is immediately apparent that the dominant strategy equilibrium of the VCM is where each individual contributes zero to the public good. Thus, none of the public good is provided by the VCM even when the social optimum calls for all of the group's resources to be devoted to its production. This equilibrium result is simply an extreme form of the familiar free-rider problem arising from the gap between the private marginal benefit $\beta_{\imath}$ and the social marginal benefit, $\sum_{i=1}^{N} \beta_{i}$, of contributing to the public good. 
Now suppose that a lottery with a prize of $R$ is held and that the proceeds of the lottery in excess of the prize will be used to fund the public good. ${ }^{3}$ For simplicity, we shall assume that if insufficient bets are made to cover the cost of the prize, then the lottery provides negative amounts of the public good. ${ }^{4}$ Thus, given the wagers of all other individuals, individual $i$ chooses a wager $x_{i} \in\left[0, e_{i}\right]$ to maximize

$$
\pi_{i}=e_{i}-x_{i}+R\left(\frac{x_{i}}{\sum_{j=1}^{N} x_{j}}\right)+\beta_{i}\left(\sum_{j=1}^{N} x_{j}-R\right),
$$

where the term multiplying $R$ gives individual $i$ 's probability of winning the lottery, which is simply his wager as a proportion of total wagers. ${ }^{5}$ Differentiating yields the first-order condition: ${ }^{6}$

$$
R \frac{\sum_{j \neq i} x_{j}}{\left(\sum_{j=1}^{N} x_{j}\right)^{2}}=1-\beta_{i}
$$

Since each individual's payoff function is globally concave, satisfaction of first-order conditions with equality is sufficient to constitute an equilibrium, and the provision of the public good, $G^{L}$ arising from a lottery is

$$
G^{L}=\sum_{i=1}^{N} x_{i}-R=R\left(\frac{\sum_{i=1}^{N} \beta_{i}-1}{N-\sum_{i=1}^{N} \beta_{i}}\right) .
$$

From this expression, we see that wagers are sufficient to fund the prize whenever it is socially optimal to provide positive amounts of the public good; that is $\sum_{i=1}^{N} x_{i} \geq R$ holds provided $\sum_{i=1}^{N} \beta_{i} \geq 1$.

The previous equation reveals three properties of lotteries with a fixed prize. First, these lotteries provide socially desirable public goods in positive amounts. Extreme free-riding, which is predicted under the voluntary contribution mechanism, does not constitute an equilibrium in the lottery. Second, note that $G^{L}$ is increasing in $R$. If $\mathrm{R}=0$, the lottery coincides with a VCM, and equilibrium public good provision is zero. Moving toward the other extreme, in the absence of binding wealth constraints, it is possible to come arbitrarily close to first-best levels of equilibrium public good provision by choosing a sufficiently large prize. Third, note that equilibrium lottery revenues will be insufficient to provide socially undesirable public goods. Moreover, all of the above results may be generalized to a quasi-linear setting with diminishing marginal utility for the public good, see Morgan (1996).

\footnotetext{
${ }^{3}$ Throughout the paper we shall refer to this mechanism generically as a lottery although, technically, we are conducting a fixed-prize raffle, which is a type of lottery in which the prize is fixed prior to wagering on the lottery and where an individual's chance of winning is simply his wager divided by total wagers.

${ }^{4}$ While this assumption is patently unrealistic, the results are unchanged by more realistically allowing the raffle to be called off and the bets returned in the event that "insufficient" wagers are made (see Morgan 1996 for details).

${ }^{5}$ The probability of winning is undefined when all individuals bet zero. We shall assume that equal probabilities of winning the raffle are given to all individuals in the group in this situation.

${ }^{6}$ Throughout the analysis, we assume that income constraints are not binding.
} 
Thus, the introduction of the lottery alleviates but does not eliminate the free-rider problem. The intuition for the success of this mechanism is that the lottery itself is a fund that contains a negative externality, since an individual reduces the expected lottery payoff of other individuals when he purchases a lottery ticket. By itself, the lottery merely represents a transfer of wealth among individuals, so the negative externality has no direct welfare implication (although the introduction of the lottery does increase the variance of income levels across individuals). Nonetheless, the negative externality effects counteract the free-rider incentives associated with the private provision of the public good in such a way that individual and social incentives are more closely aligned.

\subsection{An Example}

Let us now consider an example to illustrate the equilibrium predictions of the model. This example also proves useful in that it corresponds to a game we implement in one of our experiments.

A difference between this example and the model outlined above is the assumption of an exogenous contribution to the prize pool in the lottery or directly to the public good in the VCM. It will be evident that this alteration has no effect on equilibrium behavior, but enables us to avoid the complications associated with the potential for negative amounts of the public good being provided in the lottery. ${ }^{7}$

Suppose that two individuals are each endowed with ten tokens. Tokens may be allocated to a private fund or to a public fund. Individuals retain all privately invested tokens and receive $\beta=$ $3 / 4$ of a token for each token placed by any individual into the public fund; that is, the public fund plays the role of the public good, and the per capita marginal return (hereafter 'MPCR') is 0.75 . Since $N \beta=1.5>1$, it is socially optimal to provide positive amounts of the public good.

\section{Voluntary Contribution Mechanism}

The voluntary contribution mechanism is identical to that discussed previously with two exceptions. First, we assume that 8 tokens are contributed exogenously to the public fund.

Second, each individual can only contribute integer numbers of tokens. Thus $i$ chooses $x_{i} \in\{0,1$, $2, \ldots, 10\}$ tokens to contribute to the public fund to maximize

$$
\pi_{i}=10-x_{i}+0.75\left(x_{i}+x_{j}+8\right),
$$

taking his partner's contribution, $x_{j}$, as given.

Clearly, it is a dominant strategy for $i$ to choose $x_{i}=0$, so no contributions to the public fund are made in the unique equilibrium of the VCM. Hence the equilibrium provision of the public good in the VCM is simply 8 tokens. In equilibrium, the VCM provides a per capita return of 6 tokens from the public fund and 10 tokens from the private fund, giving a payoff of 16 tokens per capita, compared to the social optimum of 21 tokens per capita.

\section{Lottery}

In the lottery, we assume that the 8 tokens that were previously exogenously contributed to the public fund are instead used to fund a prize of 8 in the lottery. In this setup, each token contributed to the public fund gives the contributor a chance of winning the prize, and so we refer to these contributions as wagers. Thus, $i$ chooses a wager $x_{i} \in\{0,1,2, \ldots, 10\}$ of tokens to maximize

\footnotetext{
${ }^{7}$ Since MPCR is constant for all levels of public goods provision, then level effects (such as the exogenous provision of prize amounts) have no effect on marginal incentives. Hence, such level effects have no effect on equilibrium predictions.
} 


$$
\pi_{i}=10-x_{i}+8\left(\frac{x_{i}}{x_{i}+x_{j}}\right)+0.75\left(x_{i}+x_{j}\right),
$$

taking his partner's wager, $x_{j}$ as given.

By our previous analysis, it is easy to show that an equilibrium wager is $x^{L}=8$. Moreover, this equilibrium is unique. Consequently, the model predicts that the total public goods provision will be 8 tokens under the VCM and 16 under the lottery. The total public goods provision in the VCM comes entirely from exogenous contributions, not from giving by partners. In the lottery, the exogenous contributions were used to fund the prize amount; thus, public goods provisions in this mechanism are simply the total wagers of the two partners.

Thus, the lottery provides a payoff of 18 tokens per capita. In this example, the lottery public good provision is double that of the VCM.7

\section{Experiments}

Two experiments were conducted, the first consisted of four sessions conducted at The Pennsylvania State University in the Fall semester of 1995, and the second consisted of eight sessions conducted at the University of Iowa in the Fall semester of 1996. The Penn State experiment was designed to provide a sharp test of the theoretical prediction that the lottery mechanism generates greater funding for public goods than the voluntary contribution mechanism. The Iowa experiment was designed to explore the robustness of these results in a more traditional public goods laboratory environment. We describe the two experiments in turn.

\subsection{Penn State Experiment}

The Penn State experiment consisted of two sets of parallel sessions. In each set, one session used a treatment that employed VCM incentives (the P-VCM treatment), and another session used a treatment that employed Lottery incentives (P-LOT). Subjects were recruited from the undergraduate population, using posters advertising payoffs "between $\$ 6$ and $\$ 18$ for a session lasting up to 75 minutes," and upon arrival, 40 subjects were randomly allocated between two rooms. In one room 20 subjects participated in a session using our P-VCM treatment, while in the other room 20 subjects participated in a P-LOT session. ${ }^{8}$ Later in the same day, two more sessions were conducted in parallel, using identical procedures but different subjects in order to check that the outcomes of each treatment are replicable. To ensure that different sessions used the same procedures, we adopted a written protocol, which is included as an appendix. Also, we attempted to make the two treatments as similar as possible while implementing the relevant incentives.

In all four sessions, the subjects were read a set of instructions (see appendix), and given an opportunity to ask questions. Each session then consisted of two phases. In phase I, subjects were anonymously paired and played a 10-stage repeated game. In phase II, subjects were rematched and played a single-stage game against another anonymous partner.

From a strategic point of view, the two phases differ in an important way: for each subject, the rounds of phase I constitute a repeated game, whereas phase II is a one-shot game. The matching procedure also has important implications for the statistical analysis of the outcomes of the experiment. Specifically, within phase I pairs, later round behavior may reflect earlier round interactions, so the two decisions made by a phase I pair in a round should not be regarded as

\footnotetext{
${ }^{8}$ Andreoni (1995) uses parallel sessions in a similar fashion to ensure maximal comparability between alternative treatments.
} 
independent. However, interactions do not take place across phase I pairs, so in each session the decisions of the ten phase I pairs may be viewed as independent of one another. This is also true for phase II: while no longer matched, the two decisions made by a phase I pair in phase II may be dependent, but decisions across phase I pairs will be independent. ${ }^{9}$

Throughout each session, the only permitted communication between subjects was via their formal decisions. These decisions involved indicating a number of tokens to place in a group account on a decision form. Monitors waited until all subjects had made their decisions before collecting these forms and delivering them to the appropriate subjects - this preserved both the simultaneity of moves required by the theoretical model, and the anonymity of pairings. After receiving the decision forms of their partner, subjects computed and recorded their point earnings for the round, monitors checked these calculations, and then a new round began with the distribution of new decision forms.

In every round the nature of the decision task was identical: subjects were endowed with 10 tokens that they had to divide between a private and a group account. In both treatments, a token placed in the private account returned 100 points to the subject, while a token placed in the group account returned 75 points to both the subject and his or her partner. In addition, in the P-VCM treatment, 8 tokens worth of points was placed directly in the group account; thus yielding each subject 600 "bonus" points. In the P-LOT treatment, 8 tokens worth of points provided a prize of 800 "bonus" points to the winner of the lottery. A subject's chances of winning the lottery were equal to the number of tokens they contributed to the group account divided by total contributions to the group account. Following the exchange of decision forms, a lottery number was drawn, and each subject learned whether or not (s)he had won the lottery. ${ }^{10}$ Under these incentives, Nash equilibrium calls for each subject to place either 0 tokens in the group account (P-VCM) or 8 tokens in the group account (P-LOT). In either treatment, placing all tokens in the group account maximizes subject earnings.

At the end of the session subjects were privately paid their earnings from a randomly selected round at a rate of $\$ 0.25$ per 30 points. All sessions were completed in less than 75 minutes, and earnings ranged from $\$ 10.50$ to $\$ 19.75$, averaging $\$ 15.10$ per subject.

A noteworthy feature of the Penn State experiment is our use of two-person groups. Most public good experiments use groups of 4 or more. ${ }^{11}$ Since our experiment focuses on the theoretical model outlined in section 2, we regarded $N$ as a design variable, and chose it to be as small as possible in order to get a large number of independent observations from each session. This would allow clean statistical tests of treatment effects and replicability. For an initial test of the theoretical model we regarded this consideration as justification for departure from the traditional environment.

One of the drawbacks of using two-person groups is that it may make comparisons between our results and other results in the large literature on public good experiments problematic. For example, in a standard public good experiment, subjects only observe total contributions to the group account. Thus, in larger groups individual decisions are difficult to infer (except in the

\footnotetext{
${ }^{9}$ A similar matching procedure is used in Keser (1995), who conducts a statistical analysis of the effect of experience in duopoly games.

${ }^{10}$ Each pair consisted of an odd and even numbered subject. For odd numbered subjects, winning lottery numbers consisted of all numbers less than 1000p where $\mathrm{p}$ is the proportion of total tokens he or she contributed to the group account. For even numbered players, winning lottery numbers consisted of the complement of this set. The set of all lottery numbers consisted of $\{0,1,2, \ldots, 999\}$. In the event that both players contributed zero tokens, equal probabilities were assigned to each player.

${ }^{11}$ For an investigation of group size effects see Isaac and Walker (1988) and Isaac, Walker and Williams (1994).
} 
extreme cases - for example, if no tokens are invested in the group account it is easy to figure out individual decisions). In a two-person group each member can exactly infer what other members chose from their own choice and observed group outcomes. If privacy of decisions affects behavior this may create substantive differences between our environment and the traditional public good experimental environment.

We also noted two other potentially important procedural differences between the Penn State experiment and other public good experiments. First, in contrast to the matching scheme outlined above, a common scheme for implementing repeated play while minimizing repeated game effects is to randomly rematch subjects from one round to the next. Second, our subjects wrote decisions on paper, and monitors then collected these, calculated payoffs and delivered results to subjects. Many public goods experiments use computers for transmitting decisions and calculating payoffs. ${ }^{12}$

\section{2 lowa Experiment}

The preceding observations motivated a second experiment to test the prediction that lotteries alleviate free-riding in a more traditional public good environment. In this second experiment, we also decided to investigate the relationship between wagers, public good provision and two other treatment variables. One treatment was the size of the prize: the theoretical prediction is that wagers and public good provision should increase with the size of the prize. The other treatment was the return from the public good: the prediction here is that wagers and public good provision should increase with this return.

This second experiment consisted of eight sessions conducted at the University of Iowa in fall, 1996. ${ }^{13}$ Subjects were recruited from a subject pool constructed from a large number of classes in the College of Business, and were told they could earn between $\$ 5$ and $\$ 20$, depending on their decisions, for participating in a decision-making study.

Each session used 20 different subjects, seated at visually isolated computer terminals. All decision and payoff information was transmitted via these terminals. Each session consisted of 20 rounds; the first five of which being designated as practice rounds, meaning that the decisions made in these rounds would not affect earnings in any way. In other respects all rounds of a session had an identical structure.

At the beginning of each round subjects were randomly divided into four-person groups and each subject was endowed with 20 tokens. Subjects did not know which three of the other subjects in the room were also in their group, however they did know that the group configurations changed from one round to the next. ${ }^{14}$ Each subject then had to decide how many tokens to allocate to a group account, with any remaining tokens placed in the subject's private account. When all subjects had made their choice, they were informed of the total number of tokens allocated to their group account. Payoffs were then determined as the sum of points from the private account, points from the group account and bonus points. During each round subjects recorded their decisions as they made them; subjects also kept a record of their payoffs, which were computed for them according to rules described in the instructions. These rules varied across treatments, as we will explain shortly.

\footnotetext{
12 There is no consensus on whether computerization is good or bad.

${ }^{13}$ The Protocol and complete set of instructions for this experiment is included as an Appendix. The software used is available at http://les.man.ac.uk/ msrbsms/lab.htm

${ }^{14}$ In fact the random matching was conducted before the first session, and then entered into the program that linked terminals. All sessions then used this same matching pattern.
} 
At the end of the session one of rounds 6-20 was chosen at random as the one which determined earnings. Subjects received $25 \phi$ for every 50 points they earned in the randomly chosen round, and were paid this amount privately and in cash. All sessions were completed in less than 11/2 hours, and all subjects earned more than $\$ 5$. In fact, sessions were shorter and earnings were higher than we had anticipated: most sessions took less than 1 hour and many subjects earned more than $\$ 20$. Averaging across all sessions, earnings were $\$ 19.49$ per subject.

Two sessions used the I-VCM treatment: a token placed in the private account yielded 100 points to the subject, while a token placed in the group account yielded 75 points to the subject and all other members of the subject's group. Subjects in the I-VCM treatment also received 600 bonus points each round. Two further sessions used a baseline Lottery (I-LOT) treatment that was identical to the I-VCM treatment except for the awarding of bonus points. In the I-LOT treatment, instead of each group member receiving 600 bonus points, 800 bonus points were assigned to the winner of a lottery, with a subject's probability of winning being determined by his or her share of group contributions. (If no tokens were placed in the group account then all group members had an equal chance of winning the lottery.) Comparisons between I-LOT and IVCM treatments provide a test of the efficacy of lotteries relative to voluntary contributions. In theory, each subject should place zero tokens in the group account in the I-VCM treatment and 6 tokens in the I-LOT treatment.

To investigate the effect of size of prize, we conducted two more sessions using a BIGLOT treatment that were identical to the I-LOT treatment except that the prize was 1600 points. In the BIGLOT treatment predicted contributions to the group account are 12 tokens per subject. Finally, to investigate more closely the effect of linking lottery proceeds to public good provision, we conducted two more sessions using a BADLOT treatment. These were identical to the I-LOT treatment except subjects received zero points from the group account. ${ }^{15}$ Under the BADLOT incentives, predicted contributions to the group account are 6 tokens per group. This level of contributions is insufficient to provide prizes, and illustrate the theoretical result that fixed-prize lotteries are only successful when efficiency calls for positive public good provision. Comparisons between I-LOT and BADLOT treatments allow us to estimate the effect of linking lottery proceeds to public good provision, independently from love-of-gambling considerations. If subjects contribute to the group account in the I-LOT treatment only because they enjoy gambling, then decisions in the BADLOT treatment should be similar to those in the I-LOT treatment.

\section{Results}

The model of section two generates a number of implications that do not follow from alternative motives for lottery play. First, the model implies particular levels of wagering given group size, prize level, and MPCR. Second, the model implies that wagers and public good provision increase with the size of the lottery prize. Third, the model predicts that wagers and public good provision increase with the MPCR (and in fact, public good provision will be negative if the MPCR is low enough that the public good is socially undesirable). Thus, for each of our treatments we ask whether wagering behavior supports the predictions of the model. Next, a comparison of our I-LOT and BIGLOT treatments allows us to examine the relationship between prizes and wagers. Further evidence on this relationship emerges from viewing a VCM as a lottery with a prize worth zero. Finally, by comparing lotteries with different MPCRs, we examine the importance of the link to the public good relative to love of gambling motives. That

\footnotetext{
${ }^{15}$ In this treatment it was possible for a subject to earn nothing (by allocating all tokens to the group account and losing the lottery). We had previously decided to pay subjects a minimum of $\$ 5$ in this event. (In fact, the event did not occur in either session.)
} 
is, if wagering in our LOT and BIGLOT treatments reflect a love of gambling, rather than an appreciation of intended incentives, then we should expect similar levels of wagering in our BADLOT treatment. With respect to each of these points our results may be summarized as follows:

1. When the equilibrium of the lottery is "relatively efficient," average wagers are well predicted by the model. ${ }^{16}$

2. Lotteries with a relatively efficient equilibrium generate higher levels of public good provision than VCMs.

3. Lotteries are less successful in funding a socially undesirable public good.

The remainder of this section consists of an overview of the experimental results followed by a series of formal tests of the implications of the model.

\section{Overview}

The results from our VCM sessions are qualitatively similar to those from other public good experiments (see Davis and Holt, 1993 and Kagel and Roth, 1995 for surveys). Figures 1 and 2 plot the average contributions to the group account across rounds and reveals excessive contributions (relative to the equilibrium prediction), declining somewhat in later rounds. Averaging over both P-VCM sessions (Figure 1), subjects contribute $46 \%$ of their tokens to the group account in the first round, falling to $29 \%$ in round 10 and $27 \%$ in round 11 . The I-VCM sessions (Figure 2) also exhibit excessive contributions, declining from 53\% in the first round to $40 \%$ of endowments by the last round.

Figure 1 (P-VCM by round), Figure 2 (I-VCM by round) about here

Particularly noticeable in the P-VCM treatment is the decline in contributions between rounds 9 and 10. While behavior in round 9 may reflect attempts by subjects to influence the behavior of their opponent in the next round, no such motivation should exist in round 10. Round 10 is the last interaction between the pair, and as such should be viewed as a one-shot game. This fundamental difference in the strategic nature of the subgames beginning in rounds 9 and 10 may explain the difference between the results from these rounds. The results from round 11 tend to support this view since round 11 is also a one-shot game with average contributions similar to round 10 .

Figure 3 displays average contributions to the group account for the P-LOT sessions, where the predicted contribution to the group account is 8 tokens per subject, or $80 \%$ of endowments.

Actual contributions are lower than this, but increase across rounds. Averaging over both lottery sessions, contributions are about $58 \%$ of endowments in the first round, increasing to about $78 \%$ and $74 \%$ by rounds 10 and 11 respectively.

Figure 3 (P-LOT by round), Figure 4 (I-LOT by round) about here

\footnotetext{
${ }^{16}$ As a measure of "relative efficiency" we use (group earnings - minimum possible group earnings) $\div$ (maximum possible group earnings - minimum possible group earnings).
} 
Despite the fact that the equilibrium in the P-VCM treatment is supported by dominant strategies, whereas the equilibrium in the P-LOT treatment is not, the equilibrium is a superior predictor of behavior in the P-LOT treatment. This may seem surprising because, other things equal, one would regard a dominant strategy equilibrium as a more compelling solution concept than Nash equilibrium. ${ }^{17}$ Perhaps the reason the dominant strategy prediction does poorly in the P-VCM treatment is that the theoretical prediction is derived purely from the analysis of private incentives, and behaviorally, group incentives may also matter. On the other hand, the tension between individual and group incentives is less pronounced in the P-LOT treatment; indeed a theoretical rationale for lotteries, suggested by the model presented in section 2 , is that they bring individual incentives more closely in line with group incentives.

Some support for this interpretation can be found in the Iowa experiment. Figure 4 shows that average wagers in the I-LOT treatment do not converge to the Nash prediction, and in fact they remain excessive throughout both sessions. The Nash equilibrium prediction is that subjects will wager $30 \%$ of their endowments (placing 6 tokens per subject per round in the group account), and in fact, averaging over all rounds of both sessions, wagers are $55 \%$ of endowments.

However, in contrast to the P-LOT treatment, where equilibrium play induces $80 \%$ relative efficiency, equilibrium play in the I-LOT treatment induces only $30 \%$ relative efficiency. The BIGLOT treatment has a larger prize than I-LOT, and so its equilibrium is more efficient. In the equilibrium of the BIGLOT treatment, subjects wager $60 \%$ of their endowment (12 tokens per subject per round), and this yields a relative efficiency measure of $60 \%$. As shown in Figure 5, average wagers in the BIGLOT sessions are closer to the equilibrium prediction. Finally, in the BADLOT treatment, equilibrium calls for subjects to wager $7.5 \%$ of endowments (placing 1.5 tokens per subject per round in the group account), resulting in $93 \%$ relative efficiency. Observe from Figure 6 that average wagers in the BADLOT sessions substantially exceed the predicted level in the initial rounds, but decline dramatically in rounds 4-6. By the last round of the sessions, average wagers are about $12 \%$ of endowments.

Figure 5 (BIGLOT by round), Figure 6 (BADLOT by round) about here

In summary, when the Nash equilibrium prediction is more efficient, as in the P-LOT, BIGLOT or BADLOT treatments, average wagers conform to the prediction quite well. On the other hand, when the prediction is less efficient, as in the I-LOT treatment, there is excessive giving. It is intriguing that other-regarding preferences may substitute for efficient incentives; if so, theoretical comparisons may overstate the efficiency gain of the lottery mechanism.

In Figure 7, the data from the two P-VCM sessions are combined and the average round-by-round contributions are compared with the combined data from the two P-LOT sessions. Clearly, repetition influences the comparison of the two mechanisms. Average contributions to the group account are quite similar in early rounds, but diverge in later rounds. We focus on rounds 10 and 11: these rounds merit special attention because they involve one-shot games and presumably reflect the most sophisticated subject behavior. Average contributions in the P-LOT treatment exceed those from the P-VCM treatment by 4.85 (round 10) and 4.675 (round 11) tokens per subject. This is in line with the theoretical prediction that lotteries increase contributions. A further prediction is that lotteries increase public good provision, that is, the increase in

\footnotetext{
${ }^{17}$ On the other hand, Sefton and Steinberg (1997) compare contributions in two experimental environments with comparable equilibrium and efficient outcomes. In one environment the Nash equilibrium is supported by dominant strategies, in the other it is not. They find only small differences between behavior in the two environments.
} 
contributions is more than enough to provide prizes. Prize provision in the lottery sessions requires 4 tokens per subject; after accounting for prize provision, we find that the lottery increases the amount of public good provision by 0.85 (round 10) and 0.675 (round 11) tokens per subject.

Figure 7 (PSU treatments by round), Figure 8 (IA treatments by round) about here

Figure 8 compares round-by-round contributions from the four Iowa treatments, pooling over sessions. Again, the changing patterns across rounds, particularly in I-VCM and BADLOT, influence the comparison of alternative mechanisms. Focussing on the last round, we find that the average numbers of tokens contributed to the group account per subject in the various treatments are 13.825 (BIGLOT), 10.35 (LOT), 8.075 (VCM), and 2.425 (BADLOT). After noting that prize provision in the BIGLOT treatment requires 4 tokens per subject, and in the LOT and BADLOT treatments requires 2 tokens per subject, we find the attained levels of public good provision across treatments follows the predicted ordering.

\subsection{Replicability and Repetition}

Figures 1-6 allow informal comparisons of sessions that use the same procedures but different subjects. The results of these comparisons are reassuring. In each of Figures 1-6 the two series displayed appear very similar. Before proceeding further, we formalize these observations by testing for the replicability of the results in each treatment. To accomplish this in the Penn State session, we computed the average contribution of each pair of subjects for the first ten rounds of the experiment. We then used a Wilcoxon rank-sum test to compare the distributions of the two samples. We used a similar procedure for rounds 10 and 11. For the Iowa sessions, we computed average contribution by each subject for rounds 6-20 and for round 20 separately. Table 1 shows that for all treatments, we fail to reject the null hypothesis that the distributions are the same across sessions. Accordingly, we pool the results of both sessions for each treatment.

Next, we consider the effects of repetition on choices. Informal inspection of Figures 1-6 suggests that repetition has important effects in at least some of the sessions. Our VCM results are consistent with previous VCM results, in particular, Andreoni (1988), in that contributions to the group account decline significantly over the course of the experiment. This occurs regardless of whether the interaction is repeated with the same set of "partners" (as in phase I of P-VCM) or with a changing set of "strangers" (I-VCM). A similar decline in contributions to the group account is evident in the BADLOT treatment (in fact this decline resembles the life-cycle phenomenon seen in many state-run lottery games, where initial enthusiasm for the game is shortlived). Notably, and in contrast to the VCM pattern, this pattern in the BADLOT treatment is a benevolent one, as is the pattern of increasing contributions in the P-LOT treatment.

Table 2 formalizes these observations using a Wilcoxon matched-pairs test to determine whether the median contribution amounts vary across rounds in each of the treatments. For the Penn State sessions, the matched samples were constructed using the average contributions of each subject pair in the relevant round. For the Iowa sessions, each subject's contributions are treated as an individual observation. Table 2 shows that P-VCM, I-VCM, and BADLOT all showed significant decreases in contribution levels when comparing the first and last rounds, while PLOT showed significant increases. ${ }^{18}$

\footnotetext{
${ }^{18}$ Excluding practice rounds for the Iowa sessions.
} 


\subsection{Tests of Theoretical Predictions}

The preceding identification of round effects suggests that comparison of the voluntary contributions and lottery mechanisms will be sensitive to the round on which the comparison is based. We argue that results from later rounds are likely to be more informative in the sense that subjects are more familiar with the game and have a better appreciation of the link between choices and outcomes in these rounds. Thus, for the Iowa experiment we test for treatment effects by comparing final round behavior under the various treatments. For the Penn State experiment, an additional consideration is that the theoretical analysis presented in Section 2 is based on a one-shot game, and so the appropriate rounds to consider from the Penn State experiment are rounds 10 and 11: rounds 1 through 9 are strategically very different. Since we do not observe significant differences between contributions in rounds 10 and 11 of the Penn State experiment, we compare VCM and Lottery contributions using data from both rounds.

\section{Public Goods Provision}

Figures 1-6 suggest that mean final round contributions to the group account are close to theoretical predictions in the P-LOT, BIGLOT, and BADLOT treatments, but exceed equilibrium predictions in the VCM and I-LOT treatments. These informal inferences are corroborated in Table 3, which presents formal tests of the hypothesis that the median and predicted contributions are equal. As alluded to earlier, agreement between actual and predicted contributions occurs when the equilibrium of the mechanism is relatively efficient, while actual contributions are excessive when the equilibrium is relatively inefficient. Table 4 lists the relative efficiency from equilibrium play, and the relative efficiency from actual play. In the case of the VCM and I-LOT treatments subjects realized much higher relative efficiency than was predicted. In contrast, in the P-LOT, BIGLOT, and BADLOT treatments equilibrium play leads to relative efficiency in excess of $60 \%$, and attained relative efficiencies are within $10 \%$ of the predicted levels.

The model also predicts that, net of prizes, lotteries increase the provision of public goods. Table 5 lists, in the column headed "Net Provision", public good provision under each treatment after subtracting prizes. The remaining cells present results of formal tests of the null hypothesis that the treatment has no effect on net public good provision. For these tests, as with the earlier tests, we took as the unit of observation individual decisions, for the Iowa treatments, and phase I subject pairs' decisions for the Penn State treatments. However, unlike the earlier tests, the model predicts the direction of departure from the null, and so we use the relevant one-sided Wilcoxon Rank-Sum test. In each cell the normalized Wilcoxon statistic is given, and the associated one-sided $p$-value is given in parentheses.

For each comparison the statistic is positive, indicating that, net of prizes, observed contributions tend to be higher in treatments for which the model predicts they should be higher. The marginal significance level, however, varies across the several comparisons. A rough summary is that, for relatively efficient lotteries, we find support for the theoretical prediction that the introduction of a lottery increases the provision of the public good when it is socially desirable. Comparing the provision of public goods in P-LOT to P-VCM and BIGLOT to I-LOT or I-VCM, the differences are statistically significant at around the $10 \%$ significance level or lower. However, in comparing I-LOT to I-VCM, we see no statistical difference in the provision of public goods. In addition, the table highlights the sharp distinction between public good provision in the BADLOT treatment (where the public good is socially undesirable) and other lottery treatments. Particularly notable is the comparison between BADLOT than I-LOT: both treatments have an identical prize, but public good provision is higher in the I-LOT treatment.

\section{Socially Undesirable Lotteries}

Table 5 also shows that when the public good is socially undesirable, contributions are significantly reduced. In fact, despite the difficulty of identifying the equilibrium, which is asymmetric (or mixed) in individual strategies ( 2 subjects contribute 2 tokens and 2 contribute 1 
token), average contributions are quite well-predicted by the equilibrium. Since I-LOT contributions exceed the predicted level, and there is a sharp difference between the I-LOT and BADLOT predictions, the observed difference in contributions between the treatments is substantial. This leads us to conclude that the increased contributions from lotteries evidenced in the various Lottery treatments of our experiment are not simply due to a pure love of gambling. When the link between public good provision and lottery proceeds is broken, lotteries are ineffective.

Finally, we note that lotteries used to fund public goods that are not valued do generate lottery revenues, both in theory and in our experiment. In theory the revenues are insufficient to cover prizes, and in our BADLOT treatment revenues (barely) cover prizes.

\section{Conclusion}

The theory presented in this paper suggests an important rationale for the use of lotteries in the private provision of public goods. When individuals account for the benefits from public good provision, funded from lottery proceeds, it becomes rational for risk-neutral individuals to participate in such a lottery. Not only this, it becomes rational to wager to such an extent that total bets cover the cost of the prize and generate a surplus for providing the public good. This theory, based on the compensating externalities provided by the lottery, may explain the efficacy of both state lotteries and gambles offered by private charities.

While there are other explanations for the success of charitable gambling institutions and state lotteries, based on irrational behavior or risk-loving preferences for example, this theoretical model provides an interesting alternative explanation with quite different implications. Our experiments test some of these implications. Specifically, contribution amounts, public goods provision, and the role of social desirability of public goods are all examined. Many, but not all, of the predictions are confirmed in the experiments. Specifically, for relatively efficient lotteries, wagering behavior is well predicted by the theory. For less efficient lotteries we observe excessive wagering. This result is not explained by the theory, but is consistent with a growing body of evidence from experiments with voluntary contribution mechanisms, where excessive generosity is observed. In our laboratory environment, despite excessive generosity in the VCM, lotteries increase the provision of the public good. Finally, our experiment confirms the importance of the link between public good provision and lotteries: when the proceeds of the lottery failed to provide any benefits, the laboratory lottery was ineffective.

From a positive perspective, the theory represents an alternative explanation for lottery play, and our experiments support the theory to the extent that average behavior is close to that predicted in most of our lottery environments. Normative implications also follow from our laboratory evidence, which supports the theoretical predictions relating public good provision to prizes and the value of public goods. One implication is that large prize lotteries will be more successful fund-raising devices than smaller scale endeavors. Our results also suggest that charitable organizations and governments should shift the prize structure of lottery games from the currently predominant pari-mutuel framework to a fixed prize framework. ${ }^{19}$ Another implication is that the continued success of state lotteries and charitable gambling institutions will be made more likely if organizers can retain a perception among the public that the proceeds of a lottery go to a good cause. More broadly, our results offer support, both in theory and in the laboratory, for the use of fixed prize lotteries in the class of mechanisms for overcoming the free-rider problem in the decentralized provision of public goods.

\footnotetext{
${ }^{19}$ A pari-mutuel lottery, which is strategically equivalent to a voluntary contribution mechanism, allocates prizes as a percentage of total revenues from the lottery.
} 


\section{Bibliography}

Andreoni, James (1988). "Why free-ride? Strategies and learning in public goods experiments," Journal of Political Economy, 37, 291-304.

Andreoni, James (1995). “Cooperation in public-goods experiments: Kindness or Confusion?" American Economic Review, 85, 891-904.

Clotfelter, Charles, and Philip Cook . Selling Hope: StateLotteries in America, Harvard University Press, Cambridge, 1989.

Douglas, Andrew. British Charitable Gambling 1956-1994, Athlone Press, London, 1995.

Isaac, R. Mark, and James M. Walker (1988). "Group size effects in public goods provision: The voluntary contributions mechanism," Quarterly Journal of Economics, 54, 1-36.

Isaac, R. Mark, James M. Walker and Arlington Williams (1994). "Group size effects," Journal of Public Economics, .

Keser, Claudia. "Learning to Cooperate in Experiments on Multi-stage price-setting duopolies with Symmetric Costs," Mimeo, 1995.

Morgan, John. "Financing public goods by means of lotteries," Mimeo, 1996.

Sefton, Martin, and Richard Steinberg (1996), "Reward structures in public good experiments," Journal of Public Economics, 61, 263-287. 


\begin{tabular}{|l|r|r|r|}
\hline \multicolumn{5}{|c|}{ Table 1 - Tests for Replicability } \\
\hline Treatment & Rounds 1-10 & Round 10 & Round 11 \\
\hline$P-V C M$ & $-0.79(0.4274)$ & $-0.98(0.3258)$ & $-0.49(0.6232)$ \\
\hline$P-L O T$ & $-0.68(0.4963)$ & $-0.49(0.6232)$ & $-0.30(0.7624)$ \\
\hline & & & \\
\hline & Rounds 6-20 & Round 20 & \\
\hline I-VCM & $0.70(0.4819)$ & $-0.18(0.8604)$ & \\
\hline$I-L O T$ & $-0.41(0.6849)$ & $-0.09(0.9246)$ & \\
\hline$B / G L O T$ & $-1.56(0.1199)$ & $-1.46(0.1441)$ & \\
\hline BADLOT & $-0.07(0.9461)$ & $0.84(0.4017)$ & \\
\hline The first entry in each cell is z, the (normalized) Wilcoxon Rank-Sum statistic, \\
The second entry is Prob > |z|, given in parentheses \\
\hline
\end{tabular}

\begin{tabular}{|c|c|c|}
\hline \multicolumn{3}{|c|}{ Table 2 Tests for Repetition Effects } \\
\hline Treatment & Round $1 \mathrm{v}$. Round 10 & Round $10 \mathrm{v}$. Round 11 \\
\hline$P-V C M$ & $2.35(0.0187$ & $0.82(0.4115)$ \\
\hline$P-L O T$ & $-2.63(0.0085$ & $1.51(0.1305)$ \\
\hline & Round 6 v. Round 20 & \\
\hline I-VCM & $2.06(0.0391$ & \\
\hline I-LOT & $0.79(0.4317$ & \\
\hline BIGLOT & $-0.40(0.6917$ & \\
\hline$B A D L O T$ & $2.15(0.0315$ & \\
\hline
\end{tabular}

The first entry in each cell is $\mathrm{z}$, the (normalized) Wilcoxon Signed-Ranks statistic, The second entry is Prob $>|z|$, given in parentheses 


\begin{tabular}{|l|r|r|}
\hline \multicolumn{1}{|c|}{ Table 3 } & \multicolumn{2}{c|}{ Tests for Predicted Contributions } \\
\hline & \multicolumn{2}{c|}{} \\
\hline Treatment & Round 10 & Round 11 \\
\hline$P-V C M$ & 0.0026 & 0.0026 \\
\hline$P-L O T$ & 1.0000 & 0.2632 \\
\hline & & \\
\hline & Round 20 & \\
\hline$I-V C M$ & 0.0000 \\
\hline$I-L O T$ & 0.0007 & \\
\hline$B I G L O T$ & 0.2110 & \\
\hline BADLOT & 0.8746 & \\
\hline The entry in each cell is the $\mathrm{p}$-value for a two-tail test \\
that the median and predicted contributions are equal \\
\hline
\end{tabular}

\begin{tabular}{|l|r|r|r|}
\hline \multicolumn{3}{|c|}{ Table 4 } & \multicolumn{3}{c|}{ Relative Efficiency } \\
\hline & & & \\
\hline Treatment & Equilibrium & $\begin{array}{c}\text { Actual } \\
\text { Round 10 }\end{array}$ & $\begin{array}{c}\text { Actual } \\
\text { Round 11 }\end{array}$ \\
\hline P-VCM & $0 \%$ & $29 \%$ & $27 \%$ \\
\hline$P$-LOT & $80 \%$ & $78 \%$ & $74 \%$ \\
\hline & & & \\
\hline & Equilibrium & $\begin{array}{c}\text { Actual } \\
\text { Round } 20\end{array}$ & \\
\hline I-VCM & $0 \%$ & $40 \%$ & \\
\hline I-LOT & $30 \%$ & $52 \%$ & \\
\hline BIGLOT & $60 \%$ & $69 \%$ & \\
\hline BADLOT & $93 \%$ & $88 \%$ & \\
\hline
\end{tabular}




\begin{tabular}{|c|c|c|c|c|}
\hline \multicolumn{5}{|c|}{ Table 5 Public Goods Provision } \\
\hline Treatment & $\begin{array}{c}\text { Net } \\
\text { Contributions }\end{array}$ & $\begin{array}{c}P-L O T \\
\text { (Round 10) }\end{array}$ & $\begin{array}{c}P-L O T \\
\text { (Round 11) }\end{array}$ & \\
\hline $\begin{array}{l}P-V C M \\
\text { (Round 10) }\end{array}$ & 5.80 & $\begin{array}{r}1.37 \\
(0.0860)\end{array}$ & & \\
\hline $\begin{array}{l}P-V C M \\
\text { (Round 11) }\end{array}$ & 5.45 & & $\begin{array}{r}1.23 \\
(0.1092)\end{array}$ & \\
\hline $\begin{array}{l}P-L O T \\
\text { (Round 10) }\end{array}$ & 7.50 & & & \\
\hline $\begin{array}{l}\text { P-LOT } \\
\text { (Round 11) }\end{array}$ & 6.80 & & & \\
\hline & $\begin{array}{c}\text { Net } \\
\text { Contributions } \\
\end{array}$ & $\begin{array}{c}\text { I-LOT } \\
\text { (Round 20) }\end{array}$ & $\begin{array}{c}\text { BIGLOT } \\
\text { (Round 20) }\end{array}$ & $\begin{array}{c}\text { BADLOT } \\
\text { (Round 20) }\end{array}$ \\
\hline $\begin{array}{l}\text { I-VCM } \\
\text { (Round 20) }\end{array}$ & 32.30 & $\begin{array}{r}0.37 \\
(0.3573)\end{array}$ & $\begin{array}{r}1.52 \\
(0.0648)\end{array}$ & $\begin{array}{r}5.47 \\
(0.0001)\end{array}$ \\
\hline $\begin{array}{l}\text { I-LOT } \\
\text { (Round 20) }\end{array}$ & 33.40 & & $\begin{array}{r}1.26 \\
(0.1038)\end{array}$ & $\begin{array}{r}6.27 \\
(0.0001)\end{array}$ \\
\hline $\begin{array}{l}\text { BIGLOT } \\
\text { (Round 20) }\end{array}$ & 39.30 & & & $\begin{array}{r}6.87 \\
(0.0001)\end{array}$ \\
\hline $\begin{array}{l}\text { BADLOT } \\
\text { (Round 20) }\end{array}$ & 1.70 & & & \\
\hline
\end{tabular}




\section{Figures}

Figure 1. Average contributions in Penn State VCM (P-VCM) sessions.

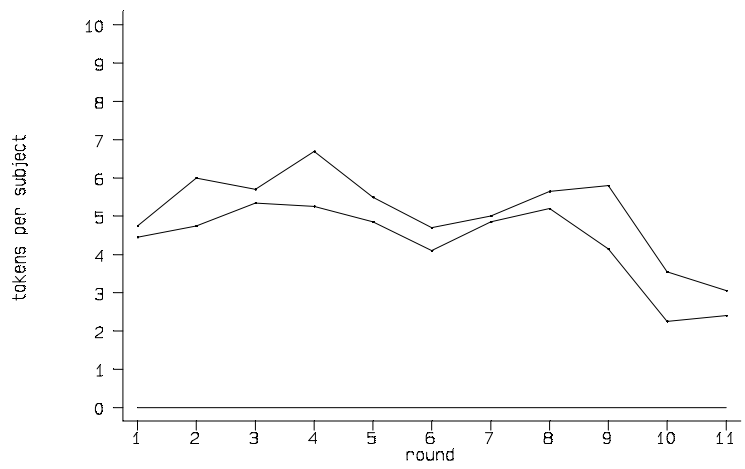

Figure 3. Average contributions in Penn State Lottery (P-LOT) sessions.

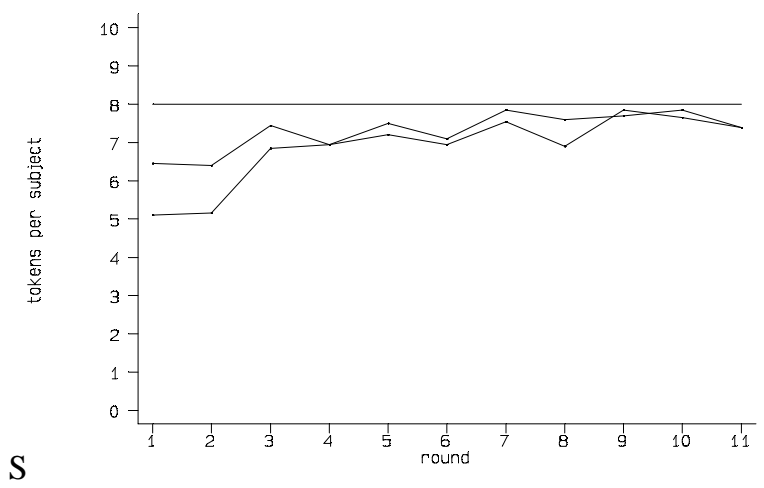

Figure 2. Average contributions in Iowa VCM (I-VCM) sessions.

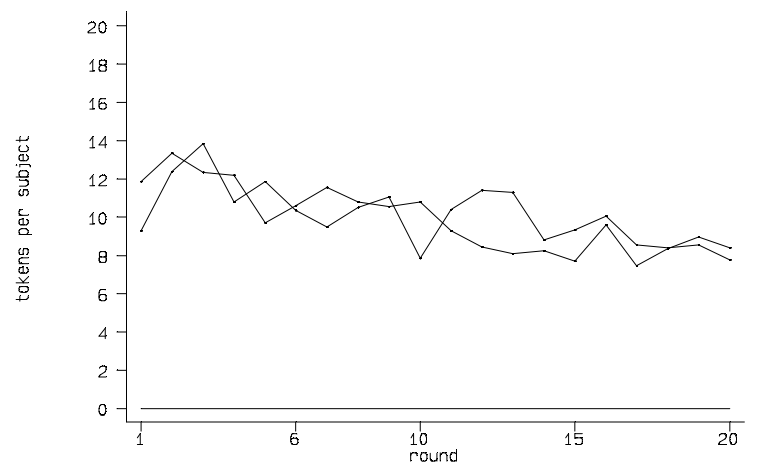

Figure 4. Average contributions in Iowa LOT (I-LOT) sessions.

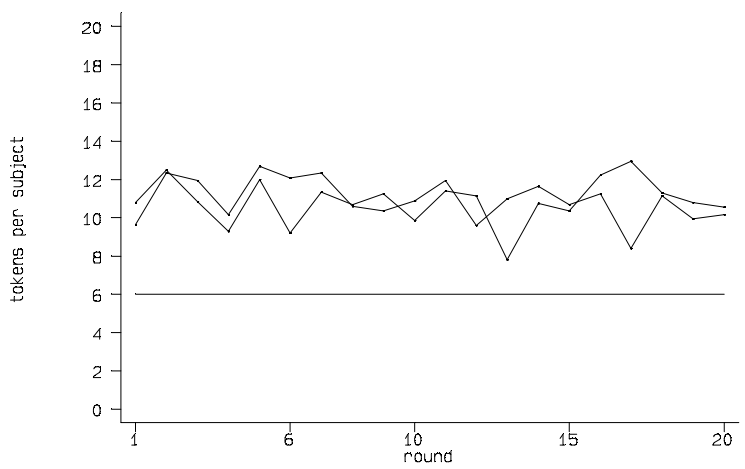


Figure 5. Average contributions in BIGLOT sessions.

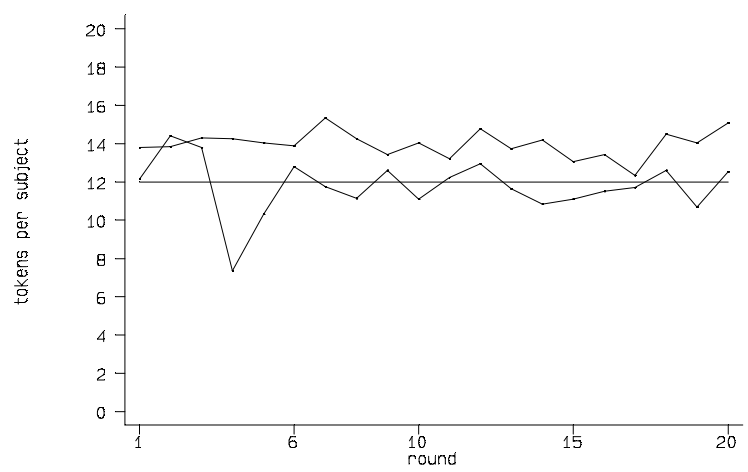

Figure 7. Average contributions in Penn State treatments.

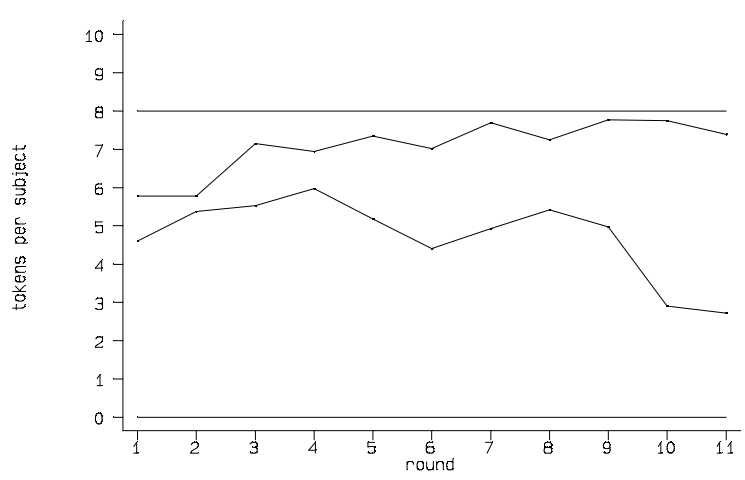

Figure 6. Average contributions in BADLOT sessions.

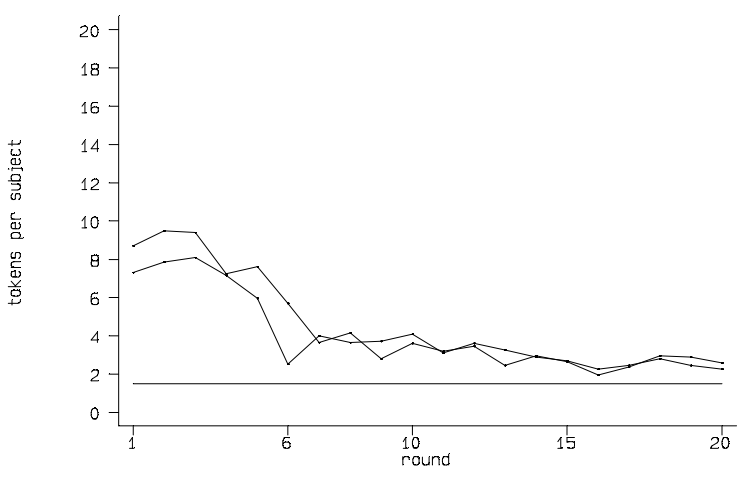

Figure 8. Average contributions in Iowa treatments.

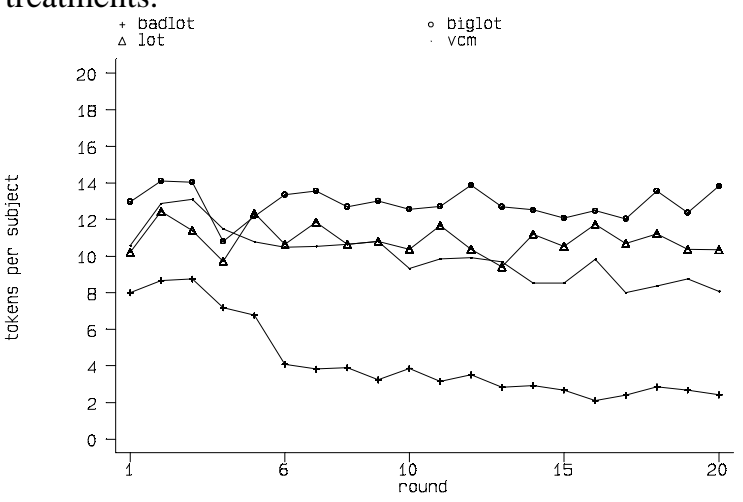




\section{Appendix}

\section{Protocol (Penn State Sessions)}

MAY I HAVE YOUR ATTENTION PLEASE. WE ARE READY TO BEGIN. THANK YOU FOR COMING. EACH OF YOU WILL BE PAID IN CASH AT THE END OF THE SESSION. WHAT YOU DO DURING THE SESSION WILL DETERMINE HOW MUCH YOU WILL BE PAID.

WITH THE EXCEPTION OF THE PEN AND FOLDER, PLEASE REMOVE ALL MATERIALS FROM THE DESK IN FRONT OF YOU AND PLACE THEM ON THE FLOOR BESIDE YOU. IN YOUR FOLDER YOU WILL FIND A SET OF INSTRUCTIONS. I WILL NOW READ OUT THE INSTRUCTIONS. AFTER HEARING THE INSTRUCTIONS YOU WILL HAVE AN OPPORTUNITY TO ASK QUESTIONS.

Read instructions.

There may be questions, answer them by referring back to the instructions if possible. If they don't need to know the answer, tell them you can't answer that question at this time.

IF THERE ARE NO (MORE) QUESTIONS, WE WILL BEGIN ROUND ONE. WHEN YOU HAVE INDICATED YOUR DECISION ON YOUR DECISION FORM, FOLD IT AND HOLD IT UP SO A MONITOR CAN COME AND GET IT.

Monitors collect forms and put them on front desk. JM/MS will sort them.

Monitors distribute forms.

[In lottery room, after decisions have been delivered state: WE'LL NOW DRAW

THE LOTTERY TICKET. Draw ticket and call out number. State: THE NUMBER WAS ???. ]

Monitors check record sheets, collect old decision forms.

[In lottery room, count number of your subjects who win the bonus. At front desk tell JM/MS how many won bonus]

Monitors distribute new decision forms.

state: WE WILL NOW BEGIN ROUND ???. WHEN YOU HAVE MADE AND RECORDED YOUR DECISION, FOLD THE DECISION FORM AND HOLD IT UP.

After the end of round 10, state: THAT'S THE END OF ROUND 10, THE NEXT ROUND WILL BE THE LAST. IN THIS ROUND YOU WILL BE PAIRED WITH A DIFFERENT PERSON FROM THE PERSON YOU HAVE BEEN PAIRED WITH SO FAR.

After end of last round, state:

THAT'S THE END OF THE LAST ROUND. NOW WE ARE GOING TO CHOOSE A NUMBER AT RANDOM, AND THE NUMBER CHOSEN WILL DETERMINE WHICH ROUND EARNINGS YOU WILL BE PAID. THIS BOX CONTAINS ELEVEN TICKETS, NUMBERED ONE TO ELEVEN.

Draw ticket and call out number. State:

THE NUMBER WAS ???. YOUR CASH EARNINGS WILL BE BASED ON THE POINTS YOU EARNED IN ROUND ???. 


\section{Instructions (Penn State Sessions)}

\section{General Rules}

This is an experiment in the economics of decision making. If you follow the instructions carefully and make good decisions you can earn a considerable amount of money. You will be paid in private and in cash at the end of the session.

There are twenty people participating in this session. It is important that you do not talk, or in any way try to communicate, with other people during the session. If you have a question, raise your hand and a monitor will come over to where you are sitting and answer your question in private.

The experiment will consist of eleven rounds. In the first ten rounds you will be paired with the same person in each of the rounds. In the eleventh round you will be paired with a different person. You will not know which of the other people in the room you are paired with, similarly, the other people in the session will not know with whom they are paired, in any round.

In each round you will have an opportunity to earn points. At the end of the session, we will randomly select one of these rounds to determine your cash earnings. You will be paid in cash at the end of the session an amount that will be determined by the number of points you earn during the randomly selected round.

\section{Description of Each Round}

At the beginning of each round you will have 10 tokens. You will choose how many of these tokens to place in a private account and how many to place in a group account. You will do this by completing a "Decision Form". You will find the decision form for round one in your folder. Look at it now.

On the first row of the decision form you will see your ID number. The second row indicates the round number. The third row tells you the ID number of the person with whom you are paired. On the fourth row you will indicate your decision. You will make your decision by indicating how many tokens you wish to place in the group account. You can enter any whole number between zero and ten, inclusive. Any tokens you do not place in the group account are placed in the private account. When you have made your decision you will enter the decision on the "Record Sheet" which you will find in your folder. Look at it now.

You will record your decision in column (b), under the heading "Tokens I Place in Group Account". At this time you will also record the number of tokens you place in the private account in column (a) under the heading "Tokens I Place in Private Account". When you have made and recorded your decision, fold your decision form and hold it up. A monitor will come and collect your form.

When all forms have been collected, the monitors will deliver your decision form to the person with whom you are paired, and will deliver their decision form to you. You will record the decision of the person with whom you are paired in column (c), headed "Tokens Other Person Places in Group Account", on your record sheet. At this time you will also record the total number of tokens placed in the group account by you and the person with whom you are paired in column (d), under the heading "Tokens in Group Account". To do this you will simply add the numbers in columns (b) and (c).

Next you will calculate your point earnings for the round according to the rules we will discuss below. When everyone has recorded their earnings correctly, the monitor will give you a new decision form and the next round will begin. 


\section{How Your Earnings are Determined}

The number of points you earn in the round will be determined as follows. For each token in your private account you will earn 100 points. You should record these earnings in column (e) of your record sheet, under the heading "My Points from Private Account". To do this simply multiply the number in column (a) by 100. Alternatively, you can read off your point earnings from the Private Account using the table provided.

In addition, for each token placed in the group account by EITHER you OR the person with whom you are paired, you will BOTH earn 75 points. You will record these earnings in column (f) under the heading "My Points from Group Account". To do this you will simply multiply the number in column (d) by 75. Alternatively, you can read off your point earnings from the Group Account using the table provided.

[VCM: In addition, in each round you will also receive some bonus points. Specifically, you will receive 600 points regardless of how you and the person you are paired place your tokens. These bonus points have already been entered on your record sheet in column (g). ]

[Lottery: In addition, in each round you may also receive 800 bonus points. Specifically, at the end of each round a lottery ticket will be drawn from a box containing 1000 tickets, numbered from 0 to 999 inclusive. In each pair, one person has an odd ID number, the other has an even ID number. If you have an odd ID number you will win 800 points if the number drawn is lower than a critical number. If you have an even ID number you will win 800 points if the number drawn is higher than a critical number. In your folder you will find a table which indicates when you will win the bonus, for all the possible token combinations. ]

[Lottery: The critical numbers in the table have been selected so that the number of tokens placed in the Group Account by you and the person with whom you are paired will determine your chances of winning the bonus. In particular, your chances of winning the bonus will be equal to the number of tokens you place in the Group Account, divided by the total number of tokens placed in the Group Account by you and the person with whom you are paired. For example, if the Group Account contains twelve tokens of which 7 were placed by you and 5 by the person with whom you are paired, you will have a 7 in 12 chance of winning the bonus, while the person with whom you are paired has a 5 in 12 chance of winning the bonus. If no tokens are placed in the Group Account, you and the person with whom you are paired will both have an equal chance of winning the bonus. ]

To compute your earnings for the round, add your earnings from columns (e), (f), and (g), and enter the result in column (h) under the heading "My Total Point Earnings for the Round".

\section{Ending the Session}

At the end of round eleven we will draw a ticket from a box. In the box are eleven tickets, numbered from one to eleven. The number on the ticket that is drawn will determine the round for which you will be paid. You will receive 25 cents in cash at the end of the session for every 30 points you earn in that round. If you have any questions raise your hand. 


\section{Protocol (Iowa Sessions)}

Login 20 subject terminals, type vcm and enter ID number. Login monitor terminal.

Seat subjects, ask them not to touch computer until we're ready. Have subjects sign consent forms. Collect consent forms. State:

MAY I HAVE YOUR ATTENTION PLEASE. WE ARE READY TO BEGIN. THANK YOU FOR COMING. EACH OF YOU WILL BE PAID IN CASH AT THE END OF THE SESSION. WHAT YOU DO DURING THE SESSION WILL DETERMINE HOW MUCH YOU WILL BE PAID.

ON YOUR DESK YOU WILL FIND A PEN AND FOLDER. YOU WILL ALSO BE USING THE COMPUTER TO MAKE DECISIONS. PLEASE REMOVE ANY OTHER MATERIALS FROM THE DESK IN FRONT OF YOU AND PLACE THEM ON THE FLOOR BESIDE YOU. IN YOUR FOLDER YOU WILL FIND A SET OF INSTRUCTIONS. I WILL NOW READ OUT THE INSTRUCTIONS. AFTER HEARING THE INSTRUCTIONS YOU WILL HAVE AN OPPORTUNITY TO ASK QUESTIONS.

Read instructions.

There may be questions, answer them by referring back to the instructions if possible. If they don't need to know the answer, tell them you can't answer that question at this time.

IF THERE ARE NO (MORE) QUESTIONS, WE WILL BEGIN ROUND ONE. YOU WILL NEED TO USE SEVERAL KEYS DURING THE EXPERIMENT. THIS SLIDE SHOWS WHERE THEY ARE ON THE KEYBOARD.

Show keyboard slide.

REMEMBER THE FIRST FIVE ROUNDS WILL NOT AFFECT YOUR CASH EARNINGS IN ANY WAY. RAISE YOUR HAND IF, AT ANY TIME, YOU HAVE A QUESTION. NOW, PRESS THE SPACE BAR AND RESPOND TO THE PROMPTS ON THE SCREEN.

After end of last round, state:

THAT'S THE END OF THE LAST ROUND. NOW WE ARE GOING TO CHOOSE A NUMBER AT RANDOM, AND THE NUMBER CHOSEN WILL DETERMINE WHICH ROUND EARNINGS YOU WILL BE PAID. THIS BOX CONTAINS 15 TICKETS, NUMBERED SIX TO TWENTY.

Draw ticket and call out number. State: 
THE NUMBER WAS ???. YOUR CASH EARNINGS WILL BE BASED ON THE POINTS YOU EARNED IN ROUND ???

On monitor terminal run endexp program. Enter cash-round.

Pay subjects at desk and collect completed receipt. A completed receipt has name, address, social security number, amount, date and signature. 


\section{Instructions (Iowa Sessions)}

$\underline{\text { General Rules }}$

This is an experiment in the economics of decision making. If you follow the instructions carefully and make good decisions you can earn a considerable amount of money. You will be paid in private and in cash at the end of the session.

There are twenty people participating in this session. It is important that you do not talk, or in any way try to communicate, with other people during the session. If you have a question, raise your hand and a monitor will come over to where you are sitting and answer your question in private.

The experiment will consist of twenty rounds. In each round you will be assigned to either group A, B, C, D, or E. Each group will consist of four people. The assignments will change from round to round. You will not know which of the other people in the room are assigned to your group, similarly, the other people in the room will not know which of the other people in the room are assigned to their group.

In each round you will have an opportunity to earn points. At the end of the session, we will randomly select one of rounds six to twenty to determine your cash earnings. Rounds one to five are practice rounds: what you do in these rounds will not affect your earnings. You will be paid in cash at the end of the session an amount that will be determined by the number of points you earn during the randomly selected round.

\section{Description of Each Round}

At the beginning of each round you will have 20 tokens. You will choose how many of these tokens to place in a private account and how many to place in a group account. You will do this using the computer keyboard.

Your computer screen will show your subject number, the round being played, and the identification number of the group to which you are assigned. When you are ready to make your choice you will press enter. When everyone is ready the computer will prompt you to make your decision. You will make your decision by indicating how many tokens you wish to place in the group account. You can enter any whole number between zero and twenty, inclusive. Any tokens you do not place in the group account are placed in the private account. If you are not satisfied with your choice you can use the backspace key to change it. When you are satisfied with your choice, you will press the enter key. Once you have pressed the enter key you have made your choice for the round and it cannot be changed. When you have made your decision you will enter the decision on the "Record Sheet" which you will find in your folder. Look at it now.

You will record your decision in column (b), under the heading "Tokens I place in the Group Account". At this time you will also record the number of tokens you place in the private account in column (a) under the heading "Tokens I Place in Private Account".

When everyone has made their decision, you will be informed of the total number of tokens placed in your group account. You will record this number on your " Record Sheet" in column (c) under the heading "Tokens in Group Account".

Next the computer will calculate and inform you of your point earnings for the round according to the rules we will discuss below. You will record this information on 
your record sheet and press the enter key when you are ready to continue. When everyone is ready the next round will begin.

\section{$\underline{\text { How Your Earnings are Determined }}$}

The number of points you earn in the round will be depend on (i) points you earn from your private account; (ii) points you earn from your group account; and (iii) bonus points. These will be determined as follows.

(i) For each token in your private account you will earn 100 points. You will record these earnings in column (d) of your record sheet, under the heading "My Points from Private Account". This will be the number in column (a) multiplied by 100 .

[VCM, LOT, BIGLOT:

(ii) For each token placed in the group account by ANY member of the group, ALL group members earn 75 points. You will record these earnings in column (e) under the heading "My Points from Group Account". This will be the number in column (c) multiplied by 75.$]$

\section{[BADLOT:}

(ii) For each token placed in the group account by ANY member of the group, ALL group members earn zero points. These earnings have already been entered on your record sheet in column (e) under the heading "My Points from Group Account".]

[VCM:

(iii) In each round you will also receive some bonus points. Specifically, you will receive 600 points regardless of how many tokens are placed in the group account. These bonus points have already been entered on your record sheet in column (f).]

\section{[LOT, BADLOT:}

(iii) In each round you may also receive 800 bonus points. Specifically, at the end of each round the computer will divide 1000 lottery numbers between the group members, and will inform you of your numbers. The computer will then randomly select a lottery number between 0 and 999 inclusive. Each number is equally likely to be selected. If the randomly selected number is one of yours, you will win 800 points.]

\section{[BIGLOT:}

(iii) In each round you may also receive 1600 bonus points. Specifically, at the end of each round the computer will divide 1000 lottery numbers between the group members, and will inform you of your numbers. The computer will then randomly select a lottery number between 0 and 999 inclusive. Each number is equally likely to be selected. If the randomly selected number is one of yours, you will win 1600 points.]

[LOT, BADLOT, BIGLOT: 
The computer selects your lottery numbers so that the number of tokens placed in the Group Account by you and the other group members determine your chances of winning the bonus. In particular, your chances of winning the bonus will be equal to the number of tokens you place in the Group Account, divided by the total number of tokens placed in the Group Account by you and all other group members. Thus, if you contributed half of the tokens to the group account, you have a 50\% chance of winning the lottery. If no tokens are placed in the Group Account then all group members have an equal chance of winning the lottery.]

To compute your earnings for the round, the computer adds your points from your private account, points from your group account, and bonus points, that is the entries in columns (d), (e) and (f). You will enter the result in column (g) under the heading "My Total Point Earnings for the Round".

\section{Ending the Session}

At the end of round twenty we will draw a ticket from a box. In the box are fifteen tickets, numbered from six to twenty. The number on the ticket that is drawn will determine the round for which you will be paid. You will receive 25 cents in cash at the end of the session for every 50 points you earn in that round. If you have any questions raise your hand. 
RECORD SHEET FOR SUBJECT

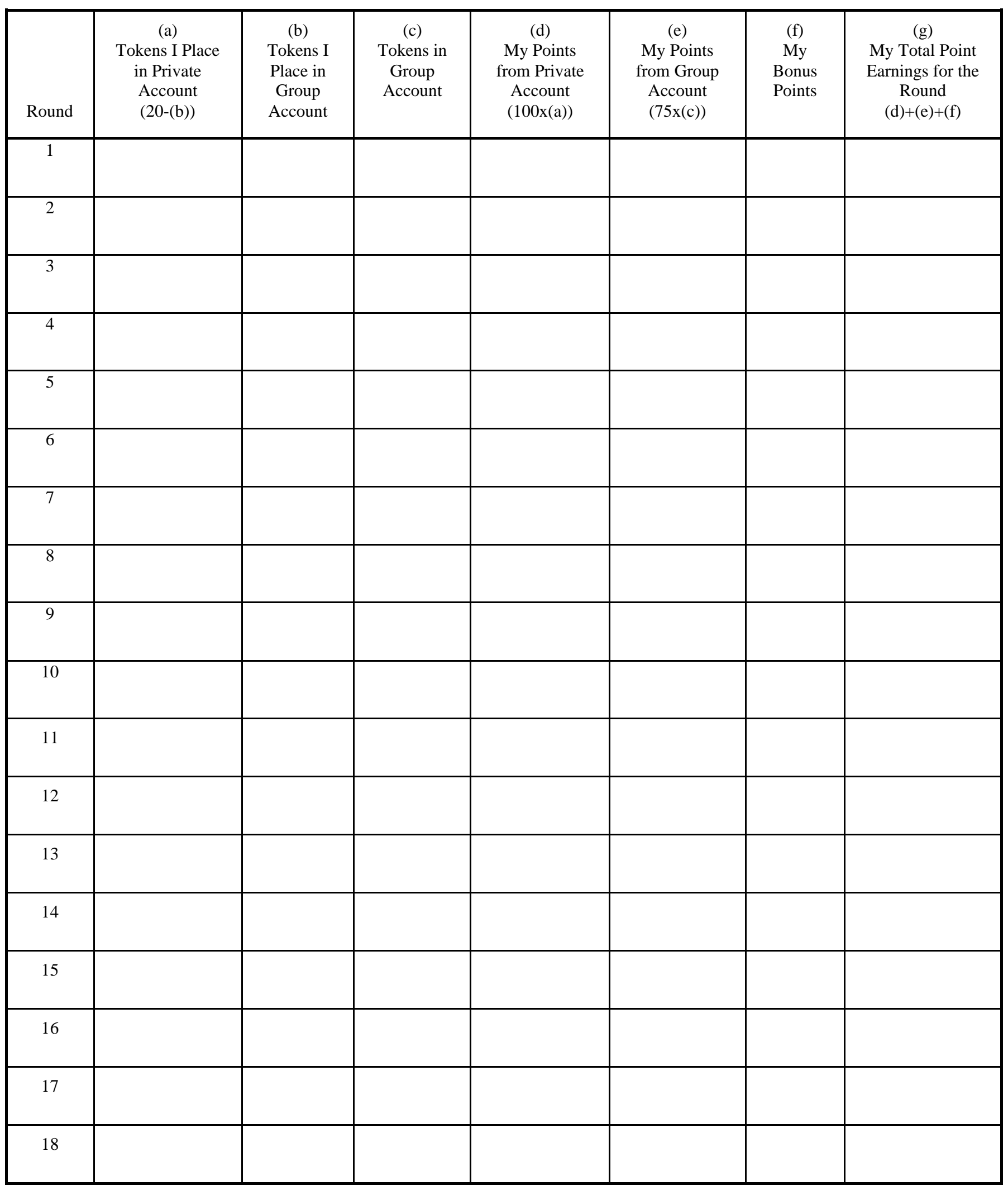




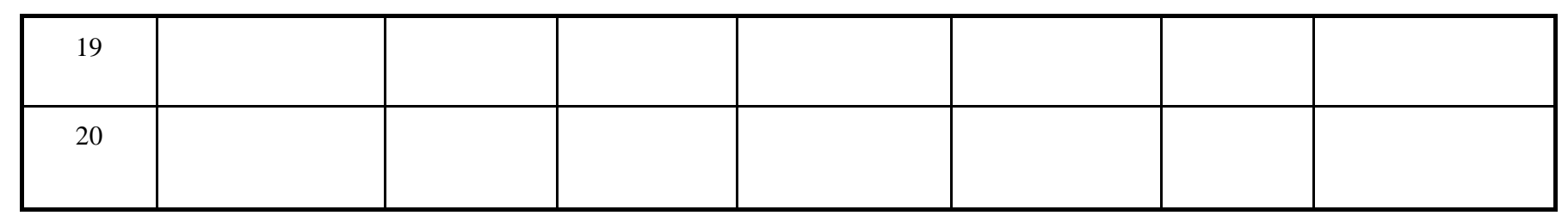

